\title{
Isoreactive Manipulation of Bioadhesive Polymers Impacts Tissue-Specific Interactions
}

\author{
Jahid Ferdous ${ }^{1}$, Eva Romito ${ }^{1,2}$, Heather Doviak ${ }^{2,3}$, Alexandra Moreira ${ }^{1}$, Mark J. Uline ${ }^{1 *}$, \\ Francis G. Spinale ${ }^{1,2,3,4}$, Tarek Shazly ${ }^{1 *}$ \\ ${ }^{1}$ College of Engineering and Computing, University of South Carolina, Columbia, SC, USA \\ ${ }^{2}$ Cardiovascular Translational Research Center, School of Medicine, University of South Carolina, Columbia, SC, USA \\ ${ }^{3}$ Department of Cell Biology and Anatomy, School of Medicine, University of South Carolina, Columbia, SC, USA \\ ${ }^{4}$ WJB Dorn Veteran Affairs Medical Center, Columbia, SC, USA \\ Email: *uline@cec.sc.edu, *shazly@mailbox.sc.edu
}

How to cite this paper: Ferdous, J., Romito, E., Doviak, H., Moreira, A., Uline, M.J., Spinale, F.G. and Shazly, T. (2017) Isoreactive Manipulation of Bioadhesive Polymers Impacts Tissue-Specific Interactions. J. Biomedical Science and Engineering, 10, 287303.

https://doi.org/10.4236/jbise.2017.105022

Received: April 4, 2017

Accepted: May 24, 2017

Published: May 27, 2017

Copyright $(9) 2017$ by authors and Scientific Research Publishing Inc. This work is licensed under the Creative Commons Attribution International License (CC BY 4.0).

http://creativecommons.org/licenses/by/4.0/ (c) (i) Open Access

\begin{abstract}
Bioadhesive polymers can serve as surgical sealants with a wide range of potential clinical applications, including augmentation of wound closure and acute induction of hemostasis. Key determinants of sealant efficacy include the strength and duration of tissue-material adhesion, as well as material biocompatibility. Canonical bioadhesive materials, however, are limited by a tradeoff among performance criteria that is largely governed by the efficiency of tissue-material interactions. In general, increasingly bioreactive materials are endowed with greater bioadhesive potential and protracted residence time, but incite more tissue damage and localized inflammation. One emergent strategy to improve sealant clinical performance is application-specific material design, with the goal of leveraging both local soft tissue surface chemistry and environmental factors to promote adhesive tissue-material interactions. We hypothesize that co-polymer systems with equivalent bioreactive group densities (isoreactive) but different amounts/oxidation states of constituent polymers will exhibit differential interactions across soft tissue types. We synthesized an isoreactive family of aldehyde-mediated co-polymers, and subjected these materials to physical (gelation time), mechanical (bulk modulus and adhesion strength), and biological (in-vitro cytotoxicity and in-vivo biocompatibility) assays indicative of sealant performance. Results show that while bioadhesion to a range of soft tissue surfaces (porcine aortic adventitia, renal artery adventitia, renal cortex, and pericardium) varies with isoreactive manipulation, general indicators of material biocompatibility remain constant. Together these findings suggest that isoreactive tuning of polymeric systems is a promising strategy to circumvent current challenges in surgical sealant applications.
\end{abstract}




\section{Keywords}

Bioadhesion, Dextran Aldehyde, Soft Tissue, Polymer, Surgical Sealant

\section{Introduction}

Bioadhesive polymeric materials have an established history of medical use, with utilities ranging from acute induction of hemostasis in cases of trauma to augmentation of wound closure in surgical applications. [1] [2] [3] Irrespective of specific use, the safety and efficacy of these materials largely depend on sufficient adherence to soft tissue surfaces, adequate residence time at the site of application, and acceptable biocompatibility. [4] Clearly, the required bioadhesive strength, material degradation/erosion kinetics, and tolerable immune/inflammatory response will all vary by application, with internal application sites subjected to high mechanical loads presenting the greatest challenge.

Bioadhesive materials can be loosely divided into two categories which exemplify the current state of sealant technologies. On the one hand, there are numerous synthetic materials which adhere vigorously to the full range of soft tissues and persist at the site of application for long periods of time. Many of these materials are based on cyanoacrylate and its derivatives, wherein adhesive bonds with soft tissues are rapidly formed in the presence of trace water. [5] [6] [7] [8] [9] Although endowed with high bioadhesive potential, these materials and their degradation by-products induce significant inflammation, confer destructive compressive mechanical forces to underlying soft tissue, and are therefore mainly used in dermal applications. Conversely, polymers based on natural compounds, most notably fibrin, are biocompatible in the context of internal applications. [10] [11] [12] However, the bioadhesion strength of these formulations is minimal, and material degradation/erosion processes are accelerated by enzymatic activity. While cyanoacrylate- and fibrin-based materials are only a small fraction of proposed technologies, their inherent limitations/tradeoffs persist to various degrees across all materials considered for soft tissue sealant applications (Table 1) [13] [14].

To address the long-standing challenges limiting sealant use and efficacy, recent efforts have focused on tissue-specific material design. [15] [16] These studies have demonstrated that polymer-based adhesive bond formation with various soft tissues is concurrently modulated by the mode of chemical bond formation and the targeted tissue surface characteristics. Moreover, the sensitivity of polymer adhesion strength to increasingly bioreactive material formulations varies with target tissue type, suggesting that in addition to careful selection of bioreactive group chemistry, optimization of bioreactive group content available for adhesive bond formation must be done on a tissue-specific basis. Building upon this theme, recent studies have shown that polymer-based adhesion can significantly vary in the context of certain disease states, providing further impetus for application-specific material design. [17] [18] Clearly, the notion of de- 
Table 1. Synthetic and natural surgical sealants. Surgical sealants are composed of a variety of base materials, including both synthetic and natural polymers. In general, current surgical sealants are limited by a tradeoff in performance criteria that is governed by the chemical mode and extent of adhesive interactions with soft tissues.

\begin{tabular}{|c|c|c|c|c|}
\hline $\begin{array}{l}\text { Classes of Sealants } \\
\text { (Base Materials) }\end{array}$ & Potential Applications & Strengths & Weaknesses & Ref \\
\hline \multicolumn{5}{|c|}{ SYNTHETIC MATERIALS } \\
\hline Cyanoacrylate & $\begin{array}{l}\text { Dermal applications; Wound } \\
\text { closure; Hernia repair }\end{array}$ & $\begin{array}{l}\text { Rapid polymerization; } \\
\text { high adhesion strength }\end{array}$ & $\begin{array}{l}\text { High toxicity of } \\
\text { degradation by-products }\end{array}$ & $23-25$ \\
\hline Polyurethane & $\begin{array}{c}\text { Orthopedic and renal surgery; } \\
\text { Pancreatic occlusion; Vascular } \\
\text { surgery }\end{array}$ & $\begin{array}{l}\text { High elasticity; } \\
\text { Moderate-high adhesion strength }\end{array}$ & $\begin{array}{c}\text { Moderate toxicity of } \\
\text { degradation by-products }\end{array}$ & $26-29$ \\
\hline Poly(ethylene glycol) & $\begin{array}{c}\text { Cranial surgery; Spinal } \\
\text { surgery; Retinal applications }\end{array}$ & $\begin{array}{l}\text { Moderate adhesion strength; High } \\
\text { biocompatibility; Soft tissue-like } \\
\text { mechanical properties }\end{array}$ & $\begin{array}{l}\text { Significant/uncontrolled } \\
\text { swelling }\end{array}$ & $30-32$ \\
\hline \multicolumn{5}{|c|}{ NATURAL MATERIALS } \\
\hline Fibrin & $\begin{array}{l}\text { Hemorrhage control; Wound } \\
\text { closure }\end{array}$ & $\begin{array}{l}\text { High biocompatibility; High } \\
\text { hemostatic potential; } \\
\text { Rapid curing in-situ }\end{array}$ & $\begin{array}{c}\text { Low adhesion strength; High } \\
\text { cost; Risk of disease } \\
\text { transmission }\end{array}$ & $33-36$ \\
\hline Albumin/glutaraldehyde & $\begin{array}{l}\text { Vascular surgery; Cardiac } \\
\text { surgery; Lung surgery }\end{array}$ & $\begin{array}{l}\text { Moderate adhesion strength; } \\
\text { Rapid cross-linking }\end{array}$ & $\begin{array}{l}\text { Toxicity of cross-linking agent; } \\
\text { Moderate biocompatibility }\end{array}$ & $37-39$ \\
\hline Collagen/Gelatin & $\begin{array}{l}\text { Lung surgery; Vascular } \\
\text { surgery; Gastrointestinal } \\
\text { surgery }\end{array}$ & $\begin{array}{l}\text { Low risk of disease transmission; } \\
\text { Low cost; Moderate-high adhe- } \\
\text { sion strength }\end{array}$ & $\begin{array}{l}\text { Toxicity of crossing-linking } \\
\text { agent; Moderate } \\
\text { biocompatibility } \\
\text { (depending on formulation) }\end{array}$ & $40-42$ \\
\hline $\begin{array}{c}\text { Polysaccharides } \\
\text { (including dextran and chitosan) }\end{array}$ & $\begin{array}{l}\text { Lung surgery; Hemorrhage } \\
\text { control }\end{array}$ & $\begin{array}{c}\text { Tunable polymer microstructure; } \\
\text { High biocompatibility; } \\
\text { Hemostatic potential }\end{array}$ & Moderate adhesion strength & $\begin{array}{c}15 ; 19-20 \\
43-44\end{array}$ \\
\hline
\end{tabular}

signing soft tissue sealants for universal deployment is fading, whereas tissueand application-specific approaches are gaining momentum.

It is well-established that increasing polymer reactive group content will promote bioadhesion, albeit to different degrees and saturation levels when applied to various soft tissue surfaces. [15] [16] These previous studies suggest that a natural variation among soft tissue surfaces may exist with regard to the availability of reactive groups targeted by sealants for adhesive bond formation. Such variance could emerge due to intrinsic differences in tissue surface composition, local environmental factors, and certain disease states. We postulate that bioadhesive co-polymer formulations with equivalent total reactive group content (isoreactive) but different reactive group distribution along constituent polymer chains will exhibit tissue-specific interactions. Moreover, because total reactive group content is associated with an increased inflammatory response, we expect that isoreactive design manipulations will not significantly impact material biocompatibility.

We synthesized a family of two-component, aldehyde-mediated bioadhesive materials composed of dextran aldehyde and chitosan polymers. In this experimental material system, both cohesive cross-linking within the material and adhesive cross-linking to local tissue surfaces are achieved through aldehyde-me- 
diated imine bond formation. Within our series of experimental materials, the dextran oxidation state and solid content are simultaneously varied such that total aldehyde concentration is fixed, i.e. this is a family of isoreactive material formulations. We assess key sealant properties and biological response variables following application of these materials to multiple soft tissue surfaces, and evaluate the potential for isoreactive tuning of bioadhesive materials to enhance tissue-specific interactions

\section{Materials and Methods}

All animals were treated and cared for in accordance with the National Institutes of Health Guide for the Care and Use of Laboratory Animals, and all protocols were approved by the University of South Carolina's Institutional Animal Care and Use Committee.

\subsection{Synthesis of Dextran Aldehyde-Chitosan Amine Co-Polymer}

Dextran oxidation The synthesis of dextran aldehyde has been previously described. [19] Briefly, a $10 \mathrm{wt}$ \% dextran solution (average molecular weight of $40 \mathrm{kDa}, 0.12 \mathrm{~mol}$ saccharide rings, Sigma no. 31389) was oxidized via dissolving the powder in deionized (DI) water. The dextran solution was subsequently mixed for five hours at room temperature with a previously prepared sodium periodate solution, which was also prepared in DI water with concentrations ranging from 5 - 15 wt.\%. Resultant solutions were equally portioned into multiple dialysis membrane tubes (molecular-weight cutoff of $3500 \mathrm{Da}$ ), and dialyzed in DI water for five days. Following dialysis, aqueous solutions were extracted, frozen with liquid nitrogen, and lyophilized for six days yielding oxidized dextran.

Aldehyde content Aldehyde content was determined via a previously described titration method. [20] Briefly, oxidized dextran powder (125 mg) was fully dissolved in $10.0 \mathrm{~mL}$ of $\mathrm{NaOH}(0.25 \mathrm{M})$ at $40^{\circ} \mathrm{C}$. Following a brief cooling period, $15.0 \mathrm{~mL}$ of $\mathrm{HCl}(0.25 \mathrm{M}), 50 \mathrm{~mL}$ DI water, and $1.0 \mathrm{~mL}$ of $0.2 \mathrm{wt} . \%$ phenolphthalein were added to the solution. A titration with $\mathrm{NaOH}(0.25 \mathrm{M})$ was then performed, with the endpoint indicated by a solution color change from clear/yellow to purple/violet. Aldehyde content was then calculated based on the titration endpoint. All variants of dextran aldehyde synthesized for these studies were characterized by the above protocol.

Chitosan synthesis A 2 wt.\% chitosan solution (average molecular weight of $340 \mathrm{kDa}$, Sigma Aldrich) and 1\% acetic acid solution were prepared and mixed at room temperature for 5 hours. The mixing period yielded a viscous homogenous solution, which was subsequently degassed and stored at room temperature until use.

Isoreactive co-polymers Four batches of dextran aldehyde with a range of percent oxidations were selected for subsequent studies. Given the aldehyde content of each batch (determined above), the wt.\% of polymer required to form aqueous solutions with equivalent total aldehyde group content (isoreactive) was 
calculated. Four isoreactive dextran aldehyde solutions (A-D) were then prepared via completely dissolving the appropriate amount of oxidized dextran in DI water.

Co-polymer material systems were formed with dextran aldehyde solutions (A-D) in combination with the prepared chitosan solution. In all co-polymer systems, the aldehyde group density (of the dextran component) was 3-fold higher than the amine group density (of the chitosan component). To facilitate co-polymer cross-linking, dextran aldehyde and chitosan solutions were loaded into a dual-chamber syringe equipped with a 12-step mixing tip. Upon injection and controlled mixing, constituent polymers react via imine bond formation to yield a solid co-polymer (Figure 1). When these materials are injected onto soft tissue surfaces, the relative excess of aldehyde groups promotes concurrent and analogous imine bond formation with tissue-present amine groups.

\subsection{Bulk Material Properties}

Gelation time The gelation time of each co-polymer formulation is defined as the time required for solid globule formation following a $100 \mu \mathrm{L}$ injection onto a glass surface maintained at $37^{\circ} \mathrm{C}$. The injected material was continuously agitated with a magnetic stirring rod, and solid globule formation was visually determined.

Compressive modulus Cylindrical test samples (diameter $=9.5 \mathrm{~mm}$ and height $=6.25 \mathrm{~mm}$ ) were prepared via co-polymer injection into a silicon mold. Samples were allowed five minutes to cross-link, after which they were carefully removed from the mold. A uniaxial mechanical testing system (Bose ${ }^{\circledast}$ Biodynamic Test Instrument, Minnetonka, MN) configured for unconfined compression testing was used to apply a ramped displacement ( $5 \mathrm{~mm}$ total displacement; displacement rate of $0.005 \mathrm{~mm} / \mathrm{sec}$ ) to each sample. Force and displacement data were continuously recorded (data acquisition rate of 20 points/sec) using an integrated system software (Wintest ${ }^{\oplus}$, Minnetonka, MN). The mechanical behavior of these materials was assumed to be linear, elastic, homogeneous, and isotropic,

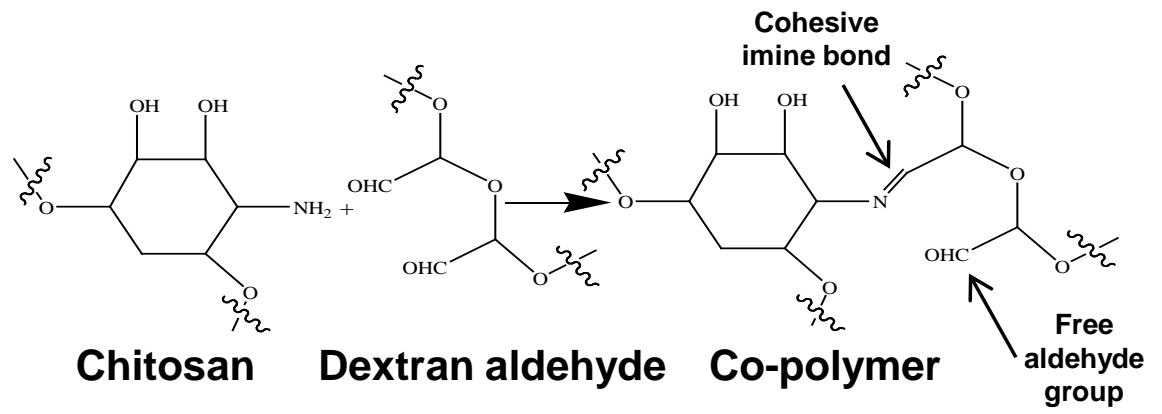

Figure 1. (a) Dextran aldehyde. The oxidation states of dextran aldehyde variants were determined via a colorimetric titration, and ranged from approximately $24 \%-72 \%$ in the present study. (b) Bioadhesive co-polymer formation. Amine groups on chitosan polymers cross-link with aldehyde groups on oxidized dextran polymers via imine bond formation. Aldehyde groups which remain free after co-polymer network formation are available for analogous bond formation with tissue-present amines. 
and the materials were modeled as incompressible solids due to the high water content. In the context of these assumptions, recorded mechanical data were processed to yield true stress versus strain curves and ultimately calculate the compressive elastic modulus (E) of each test sample (i.e. slope of the stress-strain curve).

\subsection{Adhesive Material Properties}

The morphology and mechanical strength of tissue-material interfaces formed between isoreactive co-polymer formulations (A-D) and select porcine soft tissue surfaces (aortic adventitia, renal artery adventitia, renal cortex, and pericardium) were quantified to reflect adhesive material properties. For the following ex-vivo studies, soft tissues were harvested from 7 - 12 month old swine and completed protocols within 2 hours of animal sacrifice.

Interfacial morphology To facilitate visualization of the tissue-material interface, fluorescently labeled co-polymer formulations were prepared via 0.5 wt \% inclusion of fluorescence (6-fluorescein-5-carboxyamido hexanoic acid, Invitrogen) into the chitosan component as previously described. [15] Co-polymers (100 $\mu \mathrm{L}$ total volume, via dual-chamber syringe and mixing tip) were injected onto soft tissue cylindrical biopsy specimens $(8 \mathrm{~mm}$ diameter and $1 \mathrm{~mm}$ thickness), and allowed to cross-link at room temperature under static conditions for five minutes. Samples were subsequently snap frozen, cryo-sectioned (20 um), and labeled with a nuclear dye (DAPI, Vector Laboratories ) to further delineate the adhered material from the underlying soft tissue surface. Quantitative fluorescent microscopy was used to measure the fluorescence emanating for a predefined and consistently sized material region juxtaposed to the tissue surface ( $2 \mathrm{~mm}$ along the tissue-material interface, extending $1 \mathrm{~mm}$ into the material bulk). The mean regional fluorescence $(\mathrm{N}=6)$ for each combination of material and tissue type was computed and normalized with respect to the mean bulk fluorescence of that application scenario (tissue-material pair). This relative metric reflects the degree of material continuity between the bulk co-polymer and the soft tissue surface, i.e. the continuity of the adhesive interface.

Adhesion strength Co-polymer adhesive mechanics were quantified using a previously described testing methodology. [19] [21] Briefly, tissue-material-tissue constructs were formed using two cylindrical biopsy specimens $(8 \mathrm{~mm}$ diameter and $1 \mathrm{~mm}$ thickness) of a given tissue type, between which co-polymer $(100 \mu \mathrm{L})$ was injected. Constructs were carefully mounted within a mechanical testing system (Bose ${ }^{\bowtie}$ Biodynamic Test Instrument, Minnetonka, MN) configured for uniaxial tensile testing. A compressive setting force $(1 \mathrm{~N})$ was applied to the constructs for a five minute period, followed by application of a ramped tensile displacement $(0.05 \mathrm{~mm} / \mathrm{s})$ until the occurrence of failure. Integrated system software (Wintest) continuously acquired load and displacement data, which were later processed to yield the ultimate true stress of the construct. The ultimate stress serves as an indicator of the adhesive strength of the co-polymer to the targeted soft tissue surface. 


\subsection{Material Biocompatibility}

The biocompatibility of isoreactive co-polymer formulations (A-D) was assessed via in-vitro cytotoxicity studies and in-vivo sub-cutaneous implantation studies. While neither method is directly relevant to specific sealant applications, these studies provide general indications as to whether isoreactive design manipulations within the co-polymer system will likely impact material biocompatibility.

In-vitro cytotoxicity Primary rat fibroblasts $(\sim 7 \mathrm{e} 4$ cells $/ \mathrm{mL})$ were seeded on to 24 well plates and cultured to confluence using standard media (Cell Applications, Inc.). Each well plate was then drained of media to facilitate direct injection of co-polymers $(100 \mu \mathrm{L})$ onto the cell monolayer. Materials were allowed five minutes for cross-linking, after which fresh culture media was replenished within each well plate. Following a 48 hour incubation period, a neutral red uptake (NRU) assay (Sigma Aldrich) for cell viability/cytotoxicity was performed. The assay consist of a two hour co-incubation of cells/materials with the supravital dye (neutral red), a washing treatment, and subsequent quantification of absorbance. Obtained absorbance measurements were normalized with respect to control wells (identical cell cultures with no material exposure) and reported for each co-polymer formulation (A-D).

In-vivo studies Sterile sample preparations of co-polymer formulations A-D were prepared for subcutaneous implantation in adult male Sprague Dawley rats (180 - 220 g, Charles River Labs). A randomized pattern of five discrete subcutaneous dorsal implantation sites was assigned to each rat $(n=12)$. Each of four implantation sites was assigned one co-polymer formulation (A-D), wherein a $100 \mu \mathrm{L}$ injection was sterilely delivered. The fifth implantation site was used for a sham procedure (100 $\mu \mathrm{L}$ saline injection). After 7 days, the rats were sacrificed and tissue was harvested for histological and molecular assays. For histological studies, tissue samples were fixed in $4 \%$ formalin, sectioned ( $20 \mu \mathrm{m}$ thickness), and stained with hematoxylin and eosin ( $\mathrm{H} \& \mathrm{E})$. Histological images (40X) were subjected to blind scoring, where the inflammatory cells present in four randomly selected regions $\left(25 \mathrm{~mm}^{2}\right.$ regions, total area of $100 \mathrm{~mm}^{2}$ per slide) were counted and summed. Additional tissue samples collected from each implant site ( $\mathrm{n}=3$ per material \& sham group) were snap-frozen upon acquisition and later used to quantify local interleukin (IL) levels. Tissue samples were thawed, homogenized, and analyzed using the Bio-Plex Pro Assays Quick Guide (BioRad), enabling quantification of local IL-1 $\beta$, IL-2, and IL-6 concentrations (assay sensitivity of $0.8-2.0 \mathrm{pg} / \mathrm{mL}$ ).

\subsection{Statistical Analysis}

Obtained data were analyzed using Mann-Whitney tests for significance between groups and Wilcoxon rank tests for pair-wise comparisons within groups, with groups defined by co-polymer formulation (experimental groups) or included as controls (sham procedure for in-vivo studies). Differences were considered to be significant if $p$-value $<0.05$. 


\section{Results and Discussion}

\subsection{Co-Polymer Bioreactive Group Content and Linear Distribution Parameter}

Isoreactive material synthesis yielded four dextran aldehyde-chitosan co-polymer formulations (A-D) that facilitate investigation of the proposed material design strategy (Table 2). Specifically, the dextran aldehyde components of these formulations were endowed with equivalent total aldehyde content $\left(2.3 \times 10^{20}\right.$ groups $/ \mathrm{mL}$ ), but differed in terms of oxidation states/solid content. In all formulations, the chitosan component was identical, and provided an amine group density of $7.6 \times 10^{19}$ groups $/ \mathrm{mL}$. Therefore, in all co-polymer formulations, the ratio of aldehyde: amine groups were 3:1. The relative concentrations of these groups ensure that aldehydes are available for both cohesive bond formation within the co-polymer network and adhesive bond formation with tissue-present amines. The selection of a 3:1 reactive group ratio was motivated by previous findings with an analogous material system that show a notable decline in biocompatibility with increasing free aldehyde content [19].

\subsection{Bulk Property Response to Isoreactive Design Manipulations}

Assays were conducted to determine if key intrinsic properties for surgical sealant applications vary in response to isoreactive manipulation. Specifically, the impact on co-polymer gelation kinetics (mean time for liquid-solid phase transition under controlled component mixing conditions) and the compressive elastic modulus (determined via unconfined uniaxial compression testing of cylindrical material samples) were determined. Among the examined co-polymer formulations, no significant differences were found in either mean gelation times or compressive moduli (Figure 2). These findings suggest that for these base material constituents ( $40 \mathrm{kDa}$ dextran and $340 \mathrm{kDa}$ chitosan) prepared within experimental range of dextran oxidations and solid contents, molecular mobility and steric effects within the forming co-polymer networks were similar, leading to similar rates and degrees of cross-linking.

Table 2. Co-polymer formulations. Four variants of dextran aldehyde (A-D) with titrated percent oxidation and solid contents were synthesized for this study. The solid content of each dextran aldehyde polymer within the delivery solution was tuned such that all formulations contained an equivalent aldehyde group density prior to mixing with a $2 \%$ chitosan solution. The aldehyde: amine ratio within the resultant cross-linked co-polymer systems was therefore equivalent (3:1) in all formulations.

\begin{tabular}{|c|c|c|c|c|c|c|c|c|}
\hline \multirow{3}{*}{$\begin{array}{l}\text { Co-Polymer } \\
\text { Formulation }\end{array}$} & \multicolumn{4}{|c|}{ Dextran Aldehyde } & \multicolumn{3}{|c|}{ Chitosan } & \multirow{2}{*}{$\begin{array}{c}\text { Co-Polymer } \\
\text { Reactive Group }\end{array}$} \\
\hline & Molecular & Percent & Solid & Aldehyde & Molecular & Solid & Amine & \\
\hline & Weight (kDa) & Oxidation (\%) & Content (\%) & Content (\#per mL) & Weight $(\mathrm{kDa})$ & Content (\% & Content(\#per mL) & Ratio (CHO: $\mathrm{NH}_{2}$ ) \\
\hline A & 40 & 24.3 & 10.8 & $2.30 \times 10^{20}$ & 340 & 2 & $7.63^{\star} 10^{19}$ & 3 \\
\hline $\mathrm{B}$ & 40 & 42.1 & 6.32 & $2.30 \times 10^{20}$ & 340 & 2 & $7.63 \times 10^{19}$ & 3 \\
\hline $\mathrm{C}$ & 40 & 53.5 & 4.93 & $2.30 \times 10^{20}$ & 340 & 2 & $7.63 \times 10^{19}$ & 3 \\
\hline $\mathrm{D}$ & 40 & 71.3 & 3.63 & $2.30 \times 10^{20}$ & 340 & 2 & $7.63 \times 10^{19}$ & 3 \\
\hline
\end{tabular}




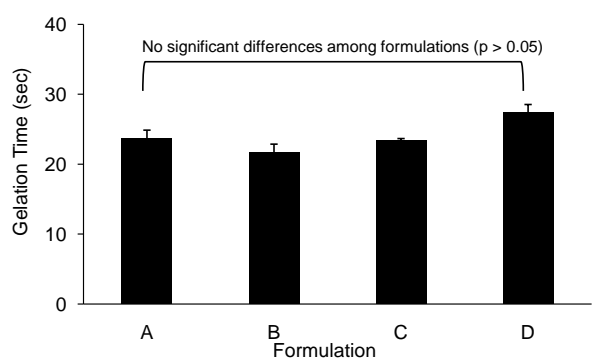

(a)

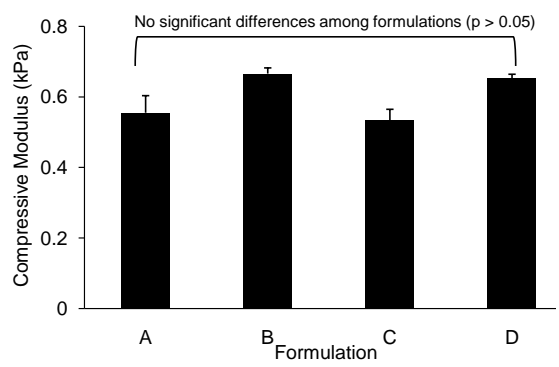

(b)

Figure 2. Bulk material properties. (a) Gelation time. Co-polymer gelation time was defined as the time to solid material formation following controlled component injection from a dual-chambered syringe equipped with a mixing tip. Co-polymer (a)-(d) gelation times ranged from 21 - 28 seconds, with no significant differences or discernable trends with respect to dextran aldehyde percent oxidation/solid content; (b) Compressive modulus. The compressive modulus of each co-polymer was determined via unconfined compression testing of cylindrical samples. Co-polymer (a)-(d) compressive moduli ranged from $0.50-0.65 \mathrm{kPa}$, with no significant differences or discernable trends with respect to dextran aldehyde percent oxidation/solid content.

\subsection{Tissue-Specific Adhesion Response to Isoreactive Design Manipulations}

The adhesive interactions between co-polymer formulations and a range of soft tissue surfaces were assessed in terms of tissue-material interfacial continuity and maximal adhesion strength. The soft tissue surfaces considered were the aortic adventitia, renal artery adventitia, renal cortex, and pericardium, all of which are potential targets for clinical sealant applications (Figure 3(a)). Significant differences in adhesion, manifested by both interfacial continuity and maximum adhesion stress prior to interfacial failure, were found among co-polymer formulations when applied to each tissue type. For example, interfacial continuity with the aortic adventitia exhibited a nonmonotonic dependence on dextran percent oxidation/solid content, and was maximal with application of formulation A (lowest percent oxidation). Conversely, interfacial continuity on renal cortex applications was insensitive to explored isoreactive manipulation (Figure 3(b)).

Similar tissue-specific responses were found when adhesion was assessed from a mechanical perspective (Figure $3(\mathrm{c})$ ). Interestingly, among the co-polymer formulations tested, the maximal adhesion strength to each tissue type occurred when the dextran percent oxidation was either its lowest (formulation A, aortic adventitia and pericardium) or highest (formulation $\mathrm{D}$, renal artery adventitia and renal cortex) value. This finding suggests that with respect to the defined mode of isoreactive variation, the optimal value for bioadhesion to each of these tissue types falls outside of the range covered by our experimental material system. Moreover, direct correlation $(\mathrm{R}=0.86$, $p$-value $<0.005)$ between tissuematerial interfacial fluorescence and maximal adhesion strength supports the interchangeability of these response variable for assessment of tissue-material adhesion (Figure 3(d)). 


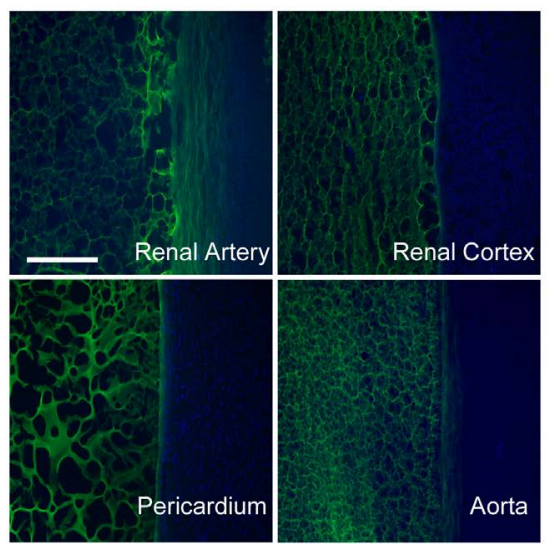

(a)

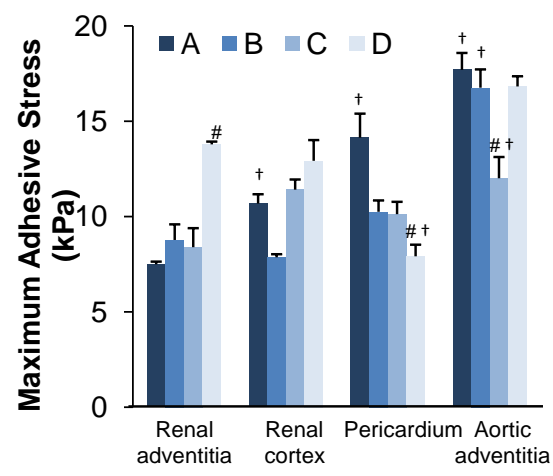

(c)

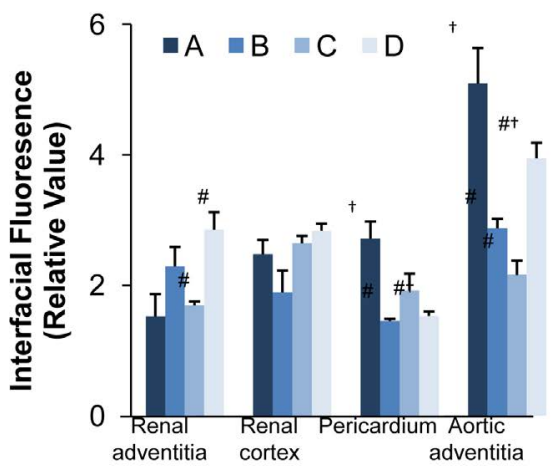

(b)

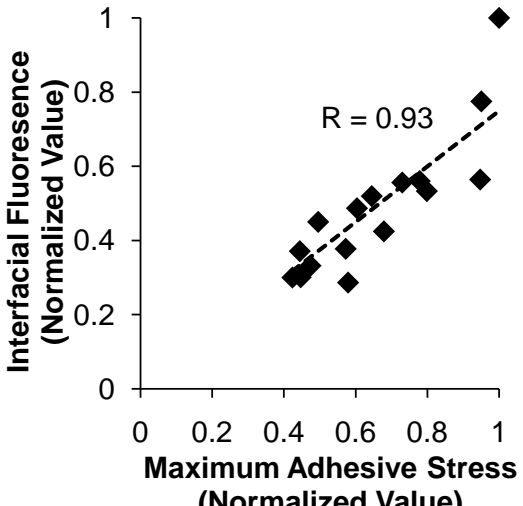

(d)

Figure 3. Adhesive material properties. (a) Qualitative interfacial morphology. Fluorescently labeled co-polymer formulations exhibit differential morphology when adhered to soft tissue surfaces, manifested as sparse and porous interfacial regions in comparison to the bulk material. Scale bar $=1 \mathrm{~mm}$ and applies to all images; (b) Quantification of interfacial fluorescence. The mean fluorescent signal emanating from predefined tissue-material interfacial regions $(2 \mathrm{~mm}$ along the tissue-material interface, extending $1 \mathrm{~mm}$ into the material bulk) were quantified and normalized with respect to the bulk material. Interfacial regions significantly differed $(p<0.05)$ in terms of various co-polymers formulations (a)-(d) adhering to a given soft tissue surface as well as a given co-polymer formulation adhering to different surfaces; (c) Adhesive mechanics. The maximal stress prior to tissue-material interfacial failure was quantified via uniaxial tensile tests on tissue-material-tissue constructs. The maximal adhesive stress significantly differed $(p<0.05)$ in terms of various co-polymers formulations (a)-(d) adhering to a given soft tissue surface as well as a given co-polymer formulation adhering to different surfaces; (d) Correlation between morphology and mechanics. Metrics to quantify interfacial morphology (B above) and mechanics (c above) exhibited a strong positive correlation ( $\mathrm{R}=0.93, P<$ 0.05 ), suggesting that adhesive strength is governed by the material continuity within the interfacial region. \# indicates significant difference of formulation (b) (c) or (d) vs. (a) with a given tissue; $\dagger$ indicates a significant difference of a given formulation interacting with renal context, pericardium, or aortic adventitia vs. the renal adventitia.

\subsection{Cell and Tissue Response to Isoreactive Design Manipulations}

Assays to determine the cytotoxic effects of formulations A-D demonstrated that co-polymer formulations are similarly tolerated by the cell culture monolayer. 
All formulations maintained greater than $58 \%$ viability of the control wells, with no significant differences in cytotoxicity among the material formulations (Figure 4). Moreover, no trend in cytotoxicity with respect to titrated polymer design variables (oxidation state and solid content) emerged among the formulations tested, suggesting that isoreactive manipulations have no discernable impact on this aspect of material biocompatibility.

While cytotoxicity assays suggest reasonable and consistent material biocompatibility, complementary subcutaneous implantation studies were undertaken to quantify and compare the in-vivo tissue response to isoreactive co-polymers. Obtained results demonstrate no significant elevations in inflammatory cell count relative to sham, and no dependence on dextran oxidation state/solid content was observed among the formulations tested (Figure 5). Tissue samples extracted from each implant site were subjected to a molecular cytokine assay, in which cytokine markers of inflammation were quantified with a rat-specific multiplex array. Relative to the sham procedure, no significant differences in cytokine concentrations were found with co-polymer implantation, and once again no trend in cytokine expression with respect to isoreactive manipulation (Figure 6). Taken together, these findings demonstrate the general biocompatibility dextran-chitosan co-polymers, and more importantly support the hypothesized insensitivity of biocompatibility to isoreactive design manipulation.

\subsection{Study Limitations}

There are several study limitations that should be considered upon interpretation of our findings. First, we have not directly shown that the surface-present biochemical groups (amine groups) targeted for adhesive bond formation in fact have different densities/spatial distributions among tissue surfaces. While beyond the scope of the present study, the tissue-present amine group distribution could be quantified with the use of functional atomic force microscopy (fAFM). [16] [22] Indeed, future studies using fAFM on soft tissue and material surfaces for the purpose of quantifying and comparing the spacing/density of the

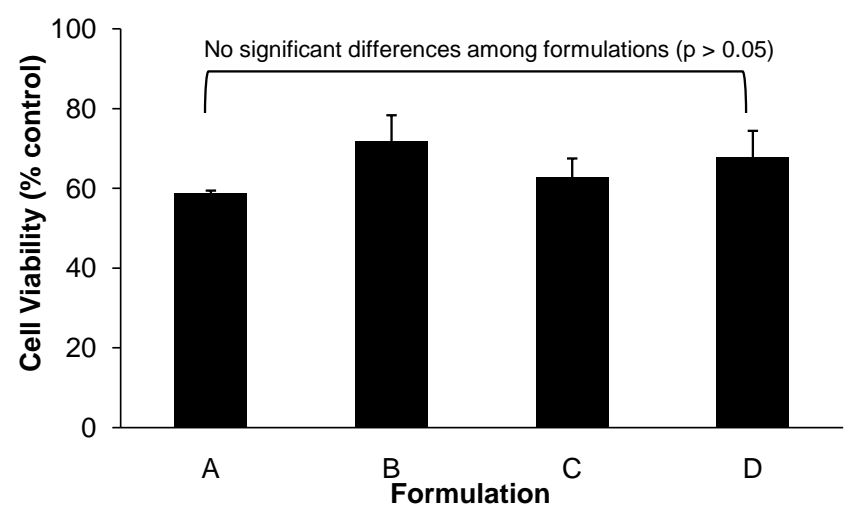

Figure 4. In-vitro cell response. The cytotoxicity of co-polymer formulations was quantified via neutral red uptake (NRU) assay formulations following direct material application to fibroblast cultures. There were no significant differences or discernable trends with respect dextran aldehyde percent oxidation/solid content. 

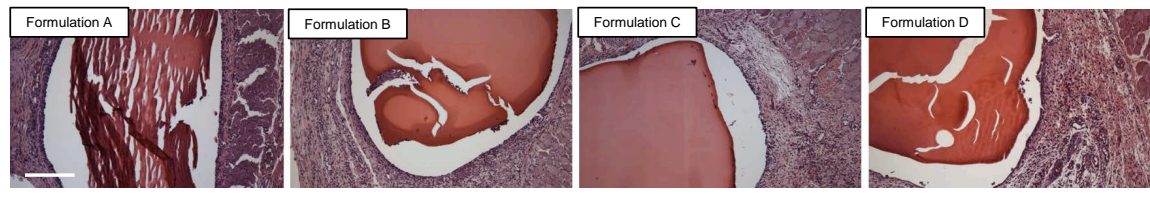

(a)

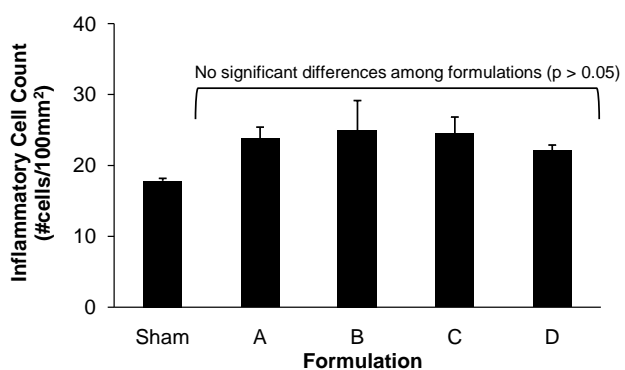

(b)

Figure 5. In-vivo inflammatory response. (a) Implant site. Co-polymer implants (light pink) are clearly visible with $\mathrm{H}$ \& $\mathrm{E}$ staining and remain intact 7 days after subcutaneous dorsal implantation in rats. Scale bar $=1 \mathrm{~mm}$ and applies to all images; (b) Inflammatory cell count. The number of inflammatory cells local to co-polymer implant was not significantly elevated with respect to sham, and there were no significant differences or discernable trends with respect to dextran aldehyde percent oxidation/solid content.

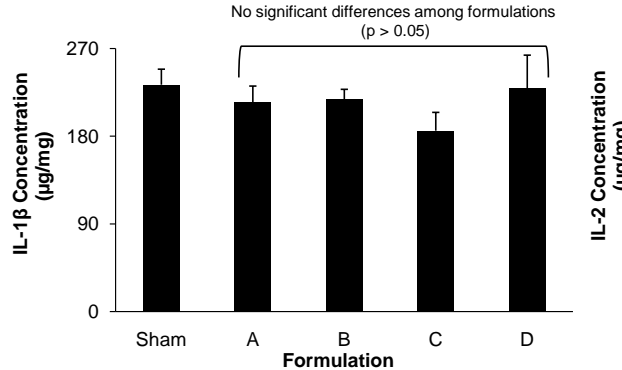

(a)

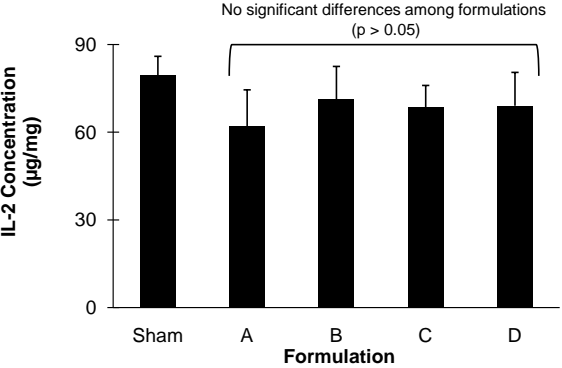

(b)

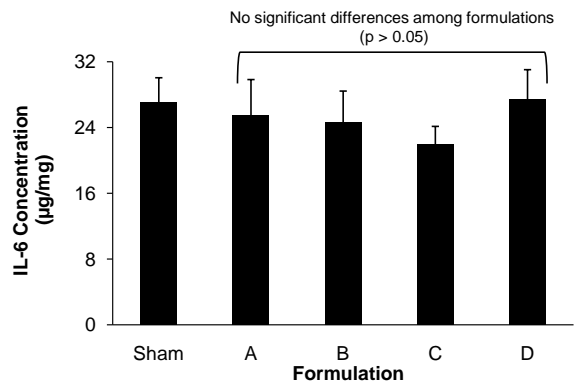

(c)

Figure 6. Cytokine activity. Select interleukin (IL) concentrations (IL-1 $\beta$, IL-2, and IL-6) in local tissue were quantified 7 days after subcutaneous dorsal implantation of co-polymers in rats. No significant elevations occured with respect to sham, and there were no significant differences or discernable trends with respect to dextran aldehyde percent oxidation/solid content.

relevant (reciprocal) reactive groups would provide a means to directly test the proposed approach to enhance bioadhesion. Second, while bioadhesion strength 
and interfacial morphology were assessed in a tissue-specific manner, we only provide general measures of material biocompatibility (in-vitro cytotoxicity and in-vivo tissue response following subcutaneous implantation). Moreover, the time point of the in-vivo studies (7 days post implantation) may have failed to detect the peak of the inflammatory response, which would likely occur upon material erosion and by-product generation. More comprehensive evaluation of the proposed design strategy, specifically the insensitivity of biocompatibility to isoreactive design manipulation, requires assessment of local tissue response in various implant scenarios and over the complete residence time of the material.

\section{Conclusion}

The aim of this study was to evaluate a novel approach for tissue-specific design of surgical sealants. Specifically, we investigated the potential for isoreactive tuning of polymer design variables to enhance tissue-material adhesion without compromising biocompatibility. Using an experimental aldehyde-mediated copolymer system, we were able to demonstrate that for select tissue types, isoreactive titration of constituent polymer oxidation state and solid content impacts bioadhesion in a tissue-specific manner, and conversely do not impact generalized indicators of material biocompatibility. These findings imply that for a given clinical application (targeted tissue type), isoreactive tuning of a surgical sealant can be optimized such that adhesion is maximized while material biocompatibility remains at a baseline level that is determined by other factors (most notably the overall bioreactive group content of the material). Although only demonstrated in our experimental material system and with a limited number of soft tissue types, we expect that this design concept can be extended to a broad range of bioadhesive materials that target a specific surface-present chemical group for adhesive bond formation.

\section{Declarations}

\section{Ethics Approval and Consent to Participate}

All animals were treated and cared for in accordance with the National Institutes of Health Guide for the Care and Use of Laboratory Animals, and all protocols were approved by the University of South Carolina's Institutional Animal Care and Use Committee.

\section{Competing Interests}

The authors declare that they have no competing interests

\section{Funding}

This research was supported by the NIH INBRE Grant for South Carolina (P20GM103499, to TS and MJU) and a VA Merit award (BX000168-06, to FGS).

\section{Authors' Contributions}

MJU, FGS, and TS conceived and designed all studies. JF, ER, AM synthesized 
and characterized all co-polymers. AM, HD, FGS performed and analyzed implantation studies. JF, MJU, FGS, and TS prepared the manuscript. All authors read and approved the final manuscript.

\section{References}

[1] Buchta, C., Hedrich, H.C., Macher, M., Hocker, P. and Redl, H. (2005) Biochemical Characterization of Autologous Fibrin Sealants Produced by CryoSeal ${ }^{\circledR}$ and Vivostat $^{\oplus}$ in Comparison to the Homologous Fibrin Sealant Product Tissucol/Tisseel ${ }^{\circledast}$. Biomaterials, 26, 6233-6241.

[2] MacGillivray, T.E. (2003) Fibrin Sealants and Glues. Journal of Cardiac Surgery, 18, 480-485. https://doi.org/10.1046/j.0886-0440.2003.02073.x

[3] Jackson MR. (1996) Tissue Sealants: Current Status, Future Potential. Nature Medicine, 2, 637-638. https://doi.org/10.1038/nm0696-637

[4] Ellman, P.I., Brett Reece, T., Maxey, T.S., Tache-Leon, C., Taylor, J.L., Spinosa, D.J., et al. (2005) Evaluation of an Absorbable Cyanoacrylate Adhesive as a Suture Line Sealant. Journal of Surgical Research, 125, 161-167.

[5] Forseth, M., O’Grady, K. and Toriumi, D.M. (1992) The Current Status of Cyanoacrylate and Fibrin Tissue Adhesives. Journal of Long-Term Effects of Medical Implants, 2, 221-233.

[6] Lamsa, T., Jin, H.T., Sand, J. and Nordback, I. (2008) Tissue Adhesives and the Pancreas: Biocompatibility and Adhesive Properties of 6 Preparations. Pancreas, 36, 261-266. https://doi.org/10.1097/MPA.0b013e31816714a2

[7] Singer, A.J., Thode Jr., H.C. (2004) A Review of the Literature on Octylcyanoacrylate Tissue Adhesive. The American Journal of Surgery, 187, 238-248. https://doi.org/10.1016/j.amjsurg.2003.11.017

[8] Ciapetti, G., Stea, S., Cenni, E., Sudanese, A., Marraro, D., Toni, A., et al. (1994) Cytotoxicity Testing of Cyanoacrylates Using Direct Contact Assay on Cell Cultures. Biomaterials, 15, 63-67.

[9] Kaplan, M. and Baysal, K. (2005) In Vitro Toxicity Test of Ethyl 2-Cyanoacrylate, a Tissue Adhesive Used in Cardiovascular Surgery, by Fibroblast Cell Culture Method. The Heart Surgery Forum, 8, E169-E172. https://doi.org/10.1532/HSF98.20041126

[10] Canonico, S. (2003) The Use of Human Fibrin Glue in the Surgical Operations. Acta Bio-Medica, 74, 21-25.

[11] Siedentop, K.H., Park, J.J., Shah, A.N., Bhattacharyya, T.K. and O'Grady, K.M. (2001) Safety and Efficacy of Currently Available Fibrin Tissue Adhesives. American Journal of Otolaryngology, 22, 230-235. https://doi.org/10.1053/ajot.2001.24817

[12] Silver, F.H., Wang, M.C. and Pins, G.D. (1995) Preparation and Use of Fibrin Glue in Surgery. Biomaterials, 16, 891-903.

[13] Annabi, N., Yue, K., Tamayol, A. and Khademhosseini, A. (2015) Elastic Sealants for Surgical Applications. European Journal of Pharmaceutics and Biopharmaceutics, 95, 27-39.

[14] Sanders, L. and Nagatomi, J. (2014) Clinical Applications of Surgical Adhesives and Sealants. Critical Reviews in Biomedical Engineering, 42, 271-292. https://doi.org/10.1615/CritRevBiomedEng.2014011676

[15] Artzi, N., Shazly, T., Baker, A.B., Bon, A. and Edelman, E.R. (2009) AldehydeAmine Chemistry Enables Modulated Biosealants with Tissue-Specific Adhesion. Advanced Materials, 21, 3399-3403. https://doi.org/10.1002/adma.200900340 
[16] Artzi, N., Zeiger, A., Boehning, F., bon Ramos, A., Van Vliet, K. and Edelman, E.R. (2011) Tuning Adhesion Failure Strength for Tissue-Specific Applications. Acta Biomaterialia, 7, 67-74.

[17] Oliva, N., Shitreet, S., Abraham, E., Stanley, B., Edelman, E.R. and Artzi, N. (2012) Natural Tissue Microenvironmental Conditions Modulate Adhesive Material Performance. Langmuir, 28, 15402-15409. https://doi.org/10.1021/la303155p

[18] Oliva, N., Unterman, S., Zhang, Y., Conde, J., Song, H.S. and Artzi, N. (2015) Personalizing Biomaterials for Precision Nanomedicine Considering the Local Tissue Microenvironment. Advanced Healthcare Materials, 4, 1584-1599. https://doi.org/10.1002/adhm.201400778

[19] Shazly, T.M., Artzi, N., Boehning, F. and Edelman, E.R. (2008) Viscoelastic Adhesive Mechanics of Aldehyde-Mediated Soft Tissue Sealants. Biomaterials, 29, 45844591. https://doi.org/10.1016/j.biomaterials.2008.08.032

[20] Artzi, N., Shazly, T., Crespo, C., Ramos, A.B., Chenault, H.K. and Edelman, E.R. (2009) Characterization of Star Adhesive Sealants Based on PEG/Dextran Hydrogels. Macromolecular Bioscience, 9, 754-765. https://doi.org/10.1002/mabi.200800355

[21] Shazly, T.M., Baker, A.B., Naber, J.R., Bon, A., Van Vliet, K.J. and Edelman, E.R. (2010) Augmentation of Postswelling Surgical Sealant Potential of Adhesive Hydrogels. Journal of Biomedical Materials Research Part A, 95A, 1159-1169. https://doi.org/10.1002/jbm.a.32942

[22] Koffas, T.S., Amitay-Sadovsky, E., Kim, J. and Somorjai, G.A. (2004) Molecular Composition and Mechanical Properties of Biopolymer Interfaces Studied by Sum Frequency Generation Vibrational Spectroscopy and Atomic Force Microscopy. Journal of Biomaterials Science,Polymer Edition, 15, 475-509. https://doi.org/10.1163/156856204323005325

[23] Jackson, C.M., Nguyen, M. and Mancini, R. (2017) Use of Cyanoacrylate Glue Casting for Stabilization of Periocular Skin Grafts and Flaps. Ophthalmic Plastic and Reconstructive Surgery, 33, 218-220.

[24] Lv, F.Y., Dong, R.H., Li, Z.J., Qin, C.C., Yan, X., He, X.X., Zhou, Y., Yan, S.Y. and Long, Y.Z. (2016) In Situ Precise Electrospinning of Medical Glue Fibers as Nonsuture Dural Repair with High Sealing Capability and Flexibility. International Journal of Nanomedicine, 11, 4213-4220. https://doi.org/10.2147/IJN.S113560

[25] Jani, K. (2016) Randomised Controlled Trial of n-Butyl Cyanoacrylate Glue Fixation versus Suture Fixation of Mesh in Laparoscopic Totally Extraperitoneal Hernia Repair. Journal of Minimal Access Surgery, 12, 118-123. https://doi.org/10.4103/0972-9941.169954

[26] Scognamiglio, F., Travan, A., Rustighi, I., Tarchi, P., Palmisano, S., Marsich, E., Borgogna, M., Donati, I., de Manzini, N. and Paoletti, S. (2016) Adhesive and Sealant Interfaces for General Surgery Applications. Journal of Biomedical Materials Research Part B, 104, 626-639. https://doi.org/10.1002/jbm.b.33409

[27] Ferreira, P., Silva, A.F., Pinto, M.I. and Gil, M.H. (2008) Development of a Biodegradable Bioadhesive Containing Urethane Groups. The Journal of Materials Science: Materials in Medicine, 19, 111-120.

https://doi.org/10.1007/s10856-007-3117-3

[28] Ferreira, P., Pereira, R., Coelho, J.F., Silva, A.F. and Gil, M.H. (2007) Modification of the Biopolymer Castor Oil with Free Isocyanate Groups to Be Applied as Bioadhesive. International Journal of Biological Macromolecules, 40, 144-152.

[29] Walgenbach, K.J., Bannasch, H., Kalthoff, S. and Rubin, J.P. (2012) Randomized, Prospective Study of TissuGlu ${ }^{\oplus}$ Surgical Adhesive in the Management of Wound 
Drainage Following Abdominoplasty. Aesthetic Plastic Surgery, 36, 491-496. https://doi.org/10.1007/s00266-011-9844-3

[30] Long, R.G., Rotman, S.G., Hom, W.W., Assael, D.J., Grijpma, D.W. and Iatridis, J.C. (2016) In Vitro and Biomechanical Screening of Polyethylene Glycol and Poly(Trimethylene Carbonate) Block Copolymers for Annulus Fibrosus Repair. Journal of Tissue Engineering and Regenerative Medicine.

[31] Hoshi, S., Okamoto, F., Arai, M., Hirose, T., Fukuda, S., Sugiura, Y. and Oshika, T. (2016) Polyethylene Glycol-Based Synthetic Hydrogel Sealant for Closing Vitrectomy Wounds: An in Vivo and Histological Study. Translational Vision Science \& Technology, 5, 7. https://doi.org/10.1167/tvst.5.3.7

[32] Hoshi, S., Okamoto, F., Arai, M., Hirose, T., Sugiura, Y., Kaji, Y. and Oshika, T. (2015) In Vivo and in Vitro Feasibility Studies of Intraocular Use of Polyethylene Glycol-Based Synthetic Sealant to Close Retinal Breaks in Porcine and Rabbit Eyes. Investigative Ophthalmology \& Visual Science, 56, 4705-4711. https://doi.org/10.1167/iovs.14-15349

[33] Li, J., Li, H.B., Zhai, X.C., Lei, Q., Jiang, X.Q. and Zhang, Z.H. (2016) Topical Use of Topical Fibrin Sealant Can Reduce the Need for Transfusion, Total Blood Loss and the Volume of Drainage in Total Knee and Hip Arthroplasty: A Systematic Review and Meta-Analysis of 1489 Patients. International Journal of Surgery, 36, 127-137.

[34] Corral, M., Ferko, N., Hogan, A., Hollmann, S.S., Gangoli, G., Jamous, N., Batiller, J. and Kocharian, R. (2016) A Hospital Cost Analysis of a Fibrin Sealant Patch in Soft Tissue and Hepatic Surgical Bleeding. ClinicoEconomics and Outcomes Research, 8, 507-519. https://doi.org/10.2147/CEOR.S112762

[35] Fuentes-Orozco, C., González-Mercado, S., Sandoval-Sandoval, J.M., Valdespino-Mejía, C., González-González, E., Ramírez-Robles, J.N., Gómez-Navarro, B., Dávalos-Delgadillo, B.E., Marquez-Leaño, L., Chávez-Tostado, M., Ramírez-Arce, A., Andalón-Dueñas, E., Espinosa-Partida, A., Macías-Amezcua, M.D. and González-Ojeda, A. (2016) Effect of Fibrin Glue on the Incidence of Surgical Complications after Living-Related-Donor Kidney Transplantation: Results of a Randomized Clinical Trial. Annals of Transplantation, 21, 587-595.

https://doi.org/10.12659/AOT.899821

[36] Brustia, R., Granger, B. and Scatton, O. (2016) An Update on Topical Haemostatic Agents in Liver Surgery: Systematic Review and Meta Analysis. Journal of Hepato-Biliary-Pancreatic Sciences, 23, 609-621. https://doi.org/10.1002/jhbp.389

[37] Bures, M., Zardo, P., Länger, F. and Zhang, R. (2016) Improved Application Technique of Albumin-Glutaraldehyde Glue for Repair of Superficial Lung Defects. Journal of Cardiothoracic Surgery, 11, 149. https://doi.org/10.1186/s13019-016-0544-6

[38] Bures, M., Höffler, H.K., Friedel, G., Kyriss, T., Boedeker, E., Länger, F., Zardo, P. and Zhang, R. (2016) Albumin-Glutaraldehyde Glue for Repair of Superficial Lung Defect: An in Vitro Experiment. Journal of Cardiothoracic Surgery, 11, 63. https://doi.org/10.1186/s13019-016-0443-x

[39] Gruber-Blum, S., Petter-Puchner, A.H., Mika, K., Brand, J., Redl, H., Ohlinger, W., Benesch, T. and Fortelny, R.H. (2010) A Comparison of a Bovine Albumin/Glutaraldehyde Glue versus Fibrin Sealant for Hernia Mesh Fixation in Experimental Onlay and IPOM Repair in Rats. Surgical Endoscopy, 24, 3086-3094. https://doi.org/10.1007/s00464-010-1094-y

[40] Mizuta, R. and Taguchi, T. (2017) Enhanced Sealing by Hydrophobic Modification of Alaska Pollock-Derived Gelatin-Based Surgical Sealants for the Treatment of Pulmonary Air Leaks. Macromolecular Bioscience, 17, Article ID: 1600349. 
[41] Binnetoglu, A., Demir, B., Yumusakhuylu, A.C., Baglam, T. and Sari, M. (2016) Use of a Gelatin-Thrombin Hemostatic Matrix for Secondary Bleeding after Pediatric Tonsillectomy. JAMA Otolaryngology—Head \& Neck Surgery, 142, 954-958. https://doi.org/10.1001/jamaoto.2016.1678

[42] Yamashita, K., Suzuki, S., Tabayashi, N., Abe, T., Hayata, Y., Hirose, T., Hiraga, S., Niwa, K., Fukuba, R., Takeda, M., Ikada, Y. and Taniguchi, S. (2015) Experimental Use of Crosslinked Gelatin Glue for Arterial Hemostasis in Cardiovascular Surgery. Bio-Medical Materials and Engineering, 25, 361-370.

https://doi.org/10.3233/bme-151534

[43] Lisman, A., Butruk, B., Wasiak, I. and Ciach, T. (2014) Dextran/Albumin Hydrogel Sealant for Dacron ${ }^{\circledR}$ Vascular Prosthesis. Journal of Biomaterials Applications, 28, 1386-1396. https://doi.org/10.1177/0885328213509676

[44] Mo, X., Iwata, H., Matsuda, S. and Ikada, Y. (2000) Soft Tissue Adhesive Composed of Modified Gelatin and Polysaccharides. Journal of Biomaterials Science Polymer, Edition, 11, 341-351. https://doi.org/10.1163/156856200743742

Submit or recommend next manuscript to SCIRP and we will provide best service for you:

Accepting pre-submission inquiries through Email, Facebook, LinkedIn, Twitter, etc. A wide selection of journals (inclusive of 9 subjects, more than 200 journals)

Providing 24-hour high-quality service

User-friendly online submission system

Fair and swift peer-review system

Efficient typesetting and proofreading procedure

Display of the result of downloads and visits, as well as the number of cited articles

Maximum dissemination of your research work

Submit your manuscript at: http://papersubmission.scirp.org/

Or contact jbise@scirp.org 